\title{
Investigation of Dosimetric Characteristics of a MOSFET Detector for Clinical Electron Beams
}

\author{
MOSFET Dedektörün Dozimetrik Karakteristik Özelliklerinin Klinik Elektron Demetleri için İncelenmesi
}

\section{Serap Çatlı Dinç, Ceren Hançer, Temur Demirci, Müge Akmansu}

Gazi University, Faculty of Medicine, Department of Radiation Oncology, Ankara, Turkey

\section{ABSTRACT}

Objective: Studying of the fundamental dosimetric characteristics of metal oxide semiconductor field effect transistor (MOSFET) detectors to evaluate its use in clinical electron beam irradiations.

Materials and Methods: In this study, GE-MS Saturne-43 linear accelerator was used. At first, Mosfet dedectors were calibrated for all electron energies. The fundamental dosimetric characteristics such as dose-linearity, reproducibility, angular dependence and field size dependence of MOSFET detectors were studied for 4,6,9,12,16 and $18 \mathrm{MeV}$ electron energies.

Results: Good linearity of the MOSFET dedector in the dose range of 10-500 cGy showed that it could be reliable detector for all electron applications. The energy dependence of a MOSFET dedector was within $3.0 \%$ for $6-18 \mathrm{MeV}$ electron beams and $8 \%$ for $4 \mathrm{MeV}$ ones. The results of the measurements performed using a spherical wax mini fantom demonstrate that the angular dependence of the MOSFET detector is small. MOSFET reproducibility is within $2 \%$.

Conclusion: This study shows that MOSFET detectors are suitable for dosimetry of electron beams in the energy range of $4-18 \mathrm{MeV}$. From the results observed it can be concluded that by applying proper calibration and correction factors, MOSFET may be used as in vivo detector for the dose verification for patients undergoing electron beam radiotherapy.

Key Words: Mosfet, in vivo dosimetry, electron beam, radiotherapy

Received: 06.04.2018

\section{ÖZET}

Amaç: Metal oksit yarilietken alan etkili transistör (MOSFET) dedektörlerin klinik elektron demetlerinde kullanımını değerlendirmek amacıyla temel dozimetrik özelliklerinin incelenmesi.

Yöntem: Çalışmada Ge marka Saturne 43 model lineer hızlandıııı kullanıılı. Öncelikle, MOSFET dedektörler tüm elektron enerjileri için kalibre edildi. 4,6,9,12,16 ve $18 \mathrm{MeV}$ elektron enerjileri için MOSFET dedektörün doz lineerliği, tekrarlanabilirliği, açıya bağımlılığı ve alan bağımlılı̆ı gibi temel dozimetrik özellikleri incelendi.

Bulgular: MOSFET dedektörün 10-500 cGy doz aralı̆̆ında iyi bir lineerlik göstermesi, tüm elektron uygulamaları için güvenilir bir dedektör olabileceğini gösterdi. MOSFET dedektörün enerji bağımlılı̆ı 6-18 MeV elektron enerjileri için \% 3.0 ve $4 \mathrm{MeV}$ için \% 8 idi. Küresel bir balmumu mini fantom kullanılarak gerçekleştirilen ölçümlerin sonuçları, MOSFET detektörünün açısal bağımlılığının küçük olduğunu göstermektedir. MOSFET tekrarlanabilirliği \% 2'dir.

Sonuç: Bu çalışma, MOSFET dedektörlerinin 4-18 MeV enerji aralığındaki elektron demetlerinin dozimetrisi için uygun olduğunu göstermektedir. Gözlemlenen sonuçlardan, uygun kalibrasyon ve düzeltme faktörleri uygulayarak MOSFET'in, elektron ışını radyoterapisi uygulanan hastalarda doz doğrulama için in vivo detektör olarak kullanılabileceği sonucuna varılabilir.

Anahtar Sözcükler: Mosfet, invivo dozimetri, elektron demeti, radyoterapi

Geliş Tarihi: 04.06.2018

Kabul Tarihi:22.06.2018 
AAPM (American Association of Physicist in Medicine) and ESTRO (European Society of Therapeutic Radiology and Oncology), like many organizations, radiotherapy is recommended that patients should be confirmed to the dose given $(1,2)$. Therefore, in vivo dosimetry has become a very important part of the quality assurance program in radiotherapy (3). Generally, TLD( Thermoluminescence dosimeters) and semiconductor diodes are used in patient dose verification (3). However, measurements using with TLD are not suitable for showing the patient dose at the moment and has many disadvantages. Likewise, large correction factors are needed at different angles, fields, and dose rates, although semiconductor diodes show the patient dose at the moment. Moreover, all of these effects are greater in electrons than in photons.

The clinical use of the TLD is limited to certain limits. It is difficult to make the samples is to be used immediately to prepare and quick calibration and are affected by environmental factors. The repeatability of measurements using TLD is not very good. This patient dosimetry is a huge problem and there is also a practical application in dosimetry studies routinely. Mosfet (Metal Oxide Silicon Semiconductor Field Effect Transistor) is a successful system for dose verification. A simple calibration procedure, instant reading, not depending on environmental conditions are just some of the advantages of using this technique (4).

These dosimeters are used in many radiotherapy and radiological applications. It has a small area $\left(0.04 \mathrm{~mm}^{2}\right)$ and many advantages, gives instant information about the dose and is suitable for multiple measurements at the same time. Also, the MOSFET is used for invivo dosimetry of IMRT (5) and skin dose measurements. Dong et al. and Bower et al. have reported on the use of a MOSFET dosimeter for diagnostic radiological applications (6).

Manigandan et al. have reported on the use of MOSFET for electron beams in the range of 4-18 MeV (7). They demonstrated that the energy dependence of a MOSFET response was within $\pm 3 \%$ for 6 - $18 \mathrm{MeV}$ electron beams and $5.5 \%$ for $4 \mathrm{MeV}$ ones. Also, MOSFET showed excellent linearity against doses measured using an ion chamber in the dose range of 20-630 cGy.

Mosfet is a dose verification system which is used to measure the accuracy of the dose given to the patient in radiotherapy, brachytherapy, radiology and treatment plan verification.

The working principle of this system is based on the measurement of the voltage accumulated in the MOSFETs in the irradiation process. This voltage is a function of the absorbed dose (6). Bloemen et al have reported that MOSFET dedectors placed on the patient's skin without additional build-up is well suited technique for dose verification in electron beams (8).

The lifetime of the MOSFET is $20000 \mathrm{mV}$. It should not be used after the $18.500 \mathrm{mV}$ (4). Because, the usage of this mosfet causes the more than $5 \%$ errors. In addiation, When at the useage of the after $16000 \mathrm{mV}$ and the measuremnets are made repeatedly, the error can ocur in up to $8 \%$ in readings beacuse of the creep-up effect that have been reported (4).

In this study, the fundamental dosimetric characteristics such as doselinearity, the angle dependency, reproducibility, field size dependence of MOSFET detectors were investigated for clinical electron energies ranging from 4 to $18 \mathrm{MeV}$. Also, we aimed to determine the dependency of the calibration factors for MOSFET dosimeter.

\section{MATERIAL and METHODS}

MOSFET is a metal oxide semiconductor known as enhanced type of field effect transistor (FET). In study, two TN-502-RD standart MOSFET detectors were used for measurements, produced by Thomson and Nielsen Electronics Ltd ( Ottawa, Canada). For the measurements, the Mosfet AutoSense system ( TN-RD-60) was used (Figure 1).

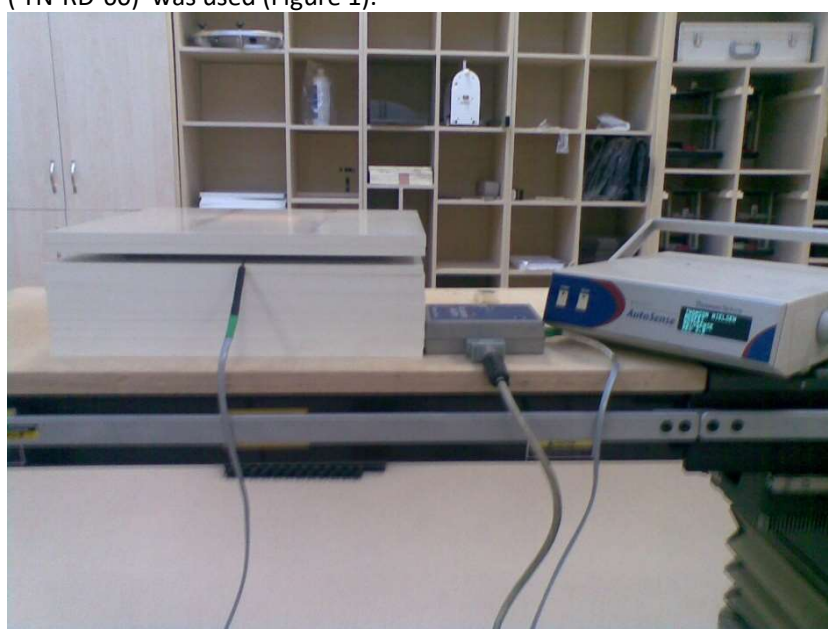

Figure 1.The set-up of Mosfet AutoSense system
Mosfet calibration was performed for electron energies using $10 \times 10 \mathrm{~cm}^{2}$ field size and $100 \mathrm{~cm}$ SSD. For all measurements were made using both of the surfaces of dosimeter as flat and round side (Figure 2).

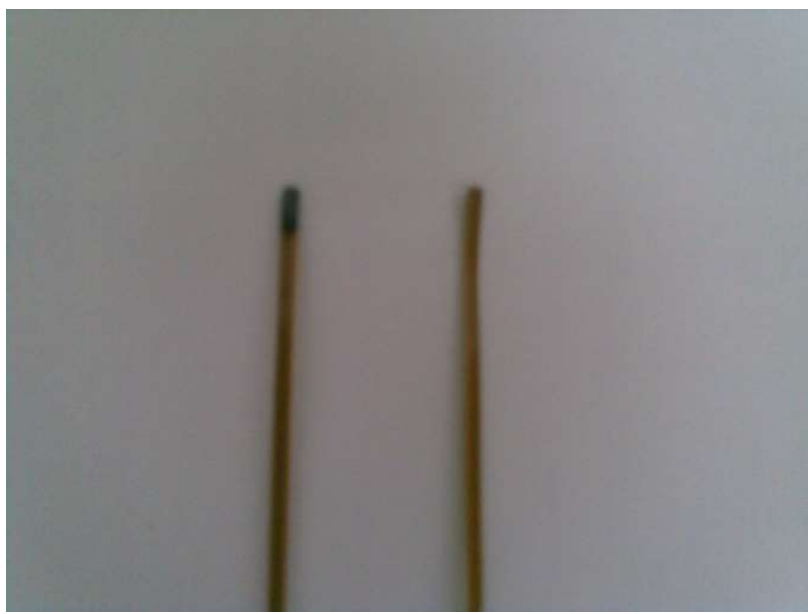

Figure 2.The both of surfaces of MOSFET dosimeter

Three measurements were performed and the results were averaged and calibration factors were defined. (Table 1 ).

Table 1. The calibration factors of two MOSFET dosimeter

\begin{tabular}{ccccc}
\hline $\begin{array}{l}\text { Electron } \\
\text { Energy }\end{array}$ & \multicolumn{2}{c}{ CF (MOSFET 1) } & ( mV/ cGy) & \multicolumn{2}{c}{ CF ( MOSFET 2) ( mV/ cGy) } \\
\hline $4 \mathrm{MeV}$ & 0.94 & 0.91 & Flat side & Round side \\
$6 \mathrm{MeV}$ & 0.95 & 0.95 & 0.96 & 0.96 \\
$9 \mathrm{MeV}$ & 0.97 & 0.98 & 1.01 & 0.99 \\
$12 \mathrm{MeV}$ & 0.99 & 0.99 & 1.01 & 1.00 \\
$16 \mathrm{MeV}$ & 1.03 & 1.03 & 1.00 & 1.03 \\
$18 \mathrm{MeV}$ & 1.02 & 1.02 & 1.04 & 1.02 \\
\hline
\end{tabular}

After calibration prosedure, the other measurements were made placing with the round side of the detector facing the beam on the center of the $30 \times 30 \times 10 \mathrm{~cm}^{3}$ RW3 solid phantom. In our institute, linear accelerators of this type are equipped with continuous variable trimmer systems. The collimating system of the linac is composed of the primary collimator and primary collimator of them can be mounted and which move simultaneously with the primary collimator opportunity $\mathrm{X} 1, \mathrm{X} 2, \mathrm{Y}$ trimmers.

\section{Dose Linearity}

The dose-linearity of Mosfet dedector in the range of $10 \mathrm{cGy}-500 \mathrm{cGy}$ was studied for all electron energies (Figure 3).

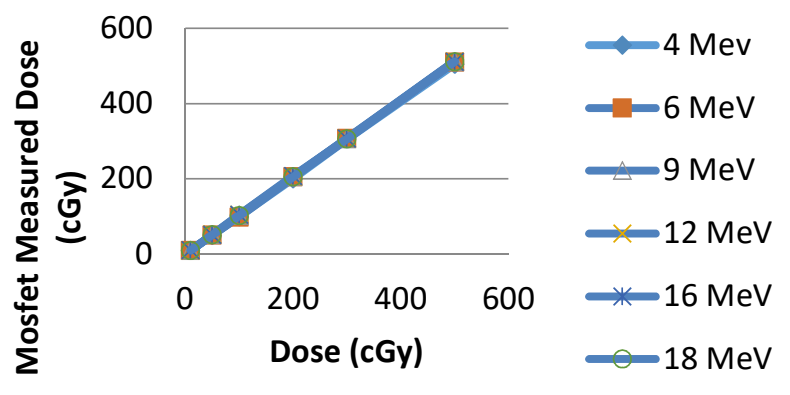

Figure 3. Linearity of the MOSFET dosimeter in the range of $10-500$ cGy measured for 4,6,9,12,16,18 MeV electron energies.

\section{Reproducibility}

The reproducibility of the Mosfet dedector at dose 200 cGy was studied for $6 \mathrm{MeV}$ electron beam. After 30 minutes waiting, the Mosfet was repeatedly exposed to 5 times in a day. (Figure 4). 


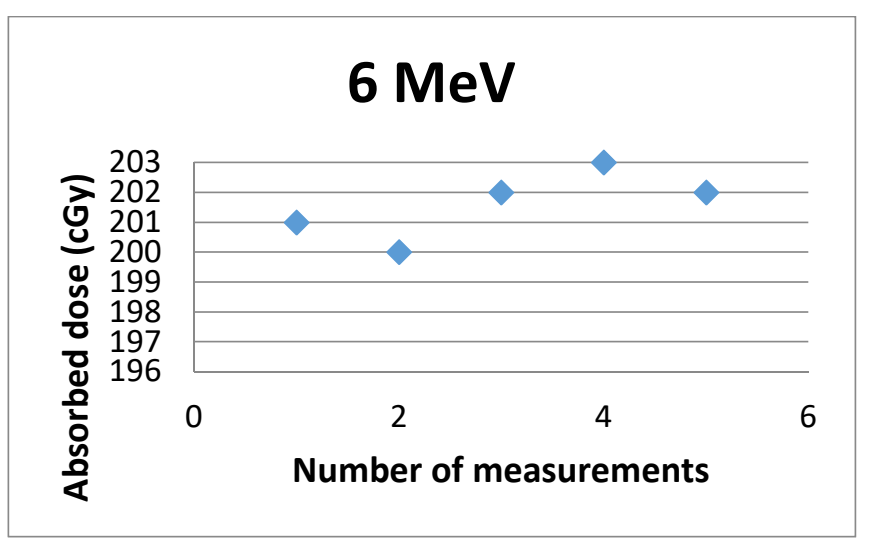

Figure 4. Reproducibility of MOSFET for $200 \mathrm{cGy}$ for $6 \mathrm{MeV}$ electron beam.

\section{Field size dependence}

To evaluate the field size dependence of Mosfet dedector, output factors were measured for all energies chancing field size from $5 \times 5 \mathrm{~cm}^{2}$ to $25 \times 25 \mathrm{~cm}^{2}$ (Table 2).

Table 2. Field size dependence of MOSFET for all energies chancing field size from $5 \times 5 \mathrm{~cm}^{2}$ to $25 \times 25 \mathrm{~cm}^{2}$

\begin{tabular}{ccccccc}
\hline Field size $\left(\mathrm{cm}^{2}\right)$ & \begin{tabular}{c}
$4 \mathrm{MeV}$ \\
\multicolumn{7}{c}{} \\
Absorbed dose \\
(cGy)
\end{tabular} & $\begin{array}{c}9 \mathrm{MeV} \\
12 \mathrm{MeV}\end{array}$ & $16 \mathrm{MeV}$ & $18 \mathrm{MeV}$ \\
\hline $5 \times 5$ & 206 & 202 & 204 & 206 & 208 & 206 \\
$10 \times 10$ & 203 & 205 & 203 & 205 & 200 & 203 \\
$15 \times 15$ & 207 & 198 & 207 & 204 & 202 & 205 \\
$20 \times 20$ & 202 & 198 & 204 & 206 & 206 & 199 \\
$25 \times 25$ & 206 & 199 & 204 & 202 & 208 & 201 \\
\hline
\end{tabular}

\section{Angular dependence}

To evaluate the angular dependence of Mosfet dedector, a spherical wax mini fantom was used. The Mosfet was placed at the center of the phantom with 2 radius. The center of the phantom was positioned in the middle of the $10 \times 10 \mathrm{~cm}^{2}$ field size at $100 \mathrm{~cm} \mathrm{SSD}$, with the round side of the detector facing the beam at $0^{\circ}$ gantry angle. The six different gantry angles were used for measurements and $6 \mathrm{MeV}$ electron energie was used. (Figure 5).

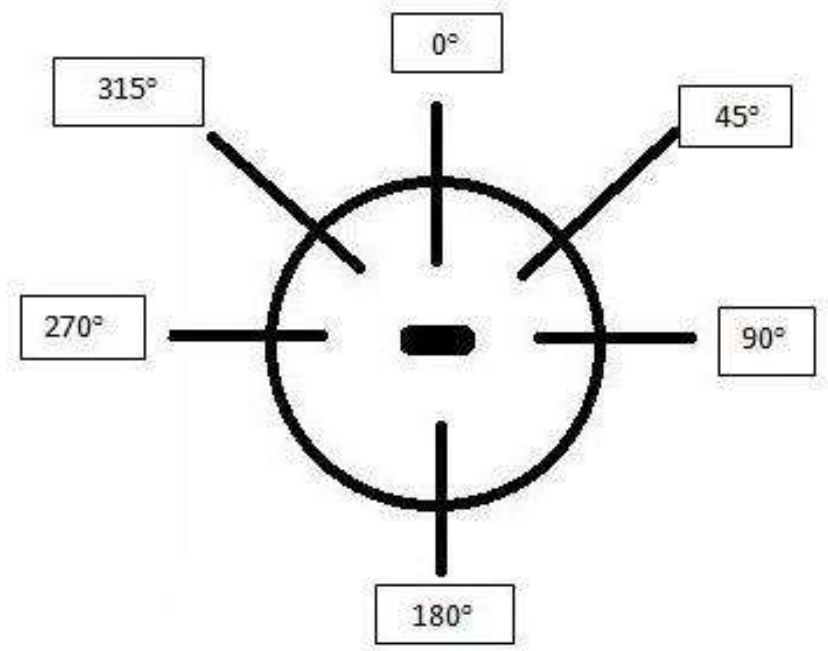

Figure 5. Experimental set-up for the determination of the angular dependence of the MOSFET

The variation in the mosfet response relative to $0^{\circ} \mathrm{K} \bullet$ was calculated using the following equation :

$\mathrm{K}_{\theta}=\frac{R(\theta=0)}{R(\theta)}$

where $R(\theta=0)$ and $\mathrm{R}(\theta)$ are the responses of the MOSFET at $0^{\circ}$ and at gantry angle $\theta$, respectively. (Figure 6 ).

\section{$6 \mathrm{MeV}$}

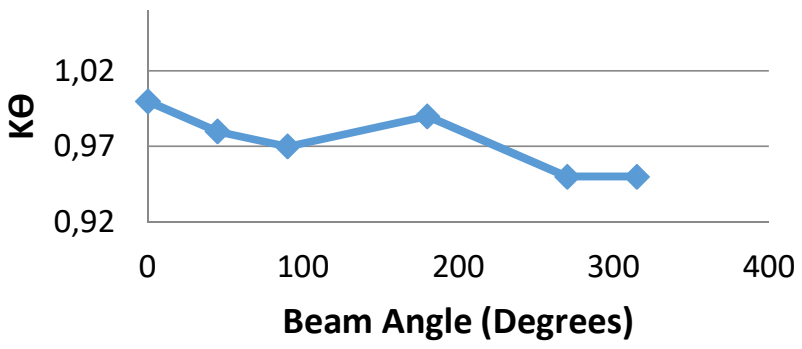

Figure 6. The dependence on the angle of the MOSFET for $6 \mathrm{MeV}$ electron energie.

In study, because of the dose rate of the linac (200 MU/min) is stable, the dose rate dependence of the Mosfet could not be measured.

\section{RESULTS}

Under the same conditions, two Mosfets with the same characters were irradiated at different positions and using different energies. As can be seen from Table 1, irradiation position and energy used irradiation affect the calibration factors. The maxiumum difference between the calibration factors were found around $3 \%$ for $6,9,12,16,18 \mathrm{MeV}$ electron energies to $4 \mathrm{MeV}$ was found around $8 \%$ difference between of the other electrons energies. In fact, the manufacturers has been reported that the energy dependence of 1-20 $\mathrm{MeV}$ electron range around $5 \%$. But the features specified by the manufacturer, as seen in our study we found out consistent results for $4 \mathrm{MeV}$. Figure 3 showed that the response to the dose of the Mosfet is linear for electron energies. For the $50 \mathrm{cGy}$ and above the $50 \mathrm{cGy}$ dose, the error was found $3 \%$. For the $10 \mathrm{cGy}$ dose, the error rate reached $8 \%$ increasingly. The figure 4 shows the values that were measured to investigate the reproducibility of the Mosfet for $6 \mathrm{MeV}$. As can be seen from the table, the maxiumum difference is about $2 \%$. Table 2 shows the values measured to examine the MOSFET field dependence. The error of readings between the low electron energies and small field sizes were found around 3\%. The error in the reading at high energies and large field sizes were reached $5 \%$.

Finally, figure 6 shows the dependence on the angle of the MOSFET for 6 $\mathrm{MeV}$ electron energie. $\mathrm{K}^{\theta}$ values vary between 0.95 and 1.00 . From these results, MOSFET depends on the angle slightly.

\section{DISCUSSION}

In our study, it was examined to investige the dosimetric properties of MOSFET dedector for use in clinical dosimetry for electron energies. MOSFET has a good linearity in the range $10-500 \mathrm{cGy}$ dose for electron enegies. Only, For the $10 \mathrm{cGy}$ radiation dose, MOSFET must be calibrated carefully and the calibration factor should be used in the measurements. MOSFETs were found to be dependent on the angle slightly.

The response of Mosfet dedector at different angles is not the same and differs from electron energies. MOSFET has two faces as the round and flat side. The flat side of Mosfet should be used, although there are not very large differences between these measurements with two faces. This is called the standard position. In the studies, it was stated that the round side of mosfet is more sensitive to radiation. It has been reported that there may be a visible dependence of the angle if the round side of the mosfet is irradiated in a faceto-face with the radiation source. The most effective way to reduce this effect, the MOSFET is to keep away from the source of radiation directly to this section. Despite not seen much of a change in the range of 6-18 MeV electron energy dependence, the same result could not be reached for $4 \mathrm{MeV}$. The observed results showed that field size dependence of the MOSFET is minimal and the MOSFET can also used for in vivo dosimetry of the patients treated with small fields. 


\section{CONCLUSIONS}

Referring to the results, when the calibration and correction factors are used, MOSFET is a simple and effective systems that can be used in the quality control program for electron energies. Ease of use, patricularly placement on a patients skin, and the permanent record of the dose reading (with the ability to confirm the reading multiple time if neceassary) are particular strenghts of this dosimeter design. These dedectors are fast, reliable,small and user friendly. Because of these advantages, MOSFET may be used as in vivo dosimeter for electron beam radiotherapy.

\section{Conflict of interest}

No conflict of interest was declared by the authors.

\section{REFERENCES}

1. Protection of the patient in radiation therapy. ICRP publication 44 . International Commission on Radiological Protection (ICRP).Ann ICRP 1985 ;15:2
2. Belleti S, Dutreix G, Garavaglia G, Gfirtner H, Haywood J, Jessen KA, et al. Quality assurance in radiotherapy: the importance of medical physics staffing levels. Recommendations from an ESTRO/EFOMP joint task group. Radiother Oncol 1996; 41: 89-94.

3. Huykens D, Bogarets R, Verstraete J, Loof M, Nystrom H, Fiorino C,et al. Practical guidelines fort he implementation of in vivo dosimetry with diodes in external beam radiotherapy with photon beams (entrance dose). Booklet no:5 ESTRO; 2001.

4. Thomson and Nielsen Electronics Ltd (Ottowa). Technical note no:4 1996

5. Marcie S, Charpiot E, Bensadour RJ,Ciasis G,Herault J,Costa A, et al. In vivo measurements with MOSFET dedectors in oropharnynx and nasopharynx intensity modulated radiotherapy. Int J Radiat Oncol Biol Phys 2005;61:16036.

6. Dong SL, Chu TC,Lan GY,Wu TH,Lin YC,Lee JS.Characterization of high sensitivity metal oxide semiconductor field effect transistor dosimeters system and LiF: Mg,Cu,P thermluminescence dosimeters for use diagnostic radiology.Appl Radiat Isot 2002;57:883-91

7. Manigandan D,Bharanidharan G,Aruna P,Devan K, Elangovan D, Patil V, Tamilarasan R, Vasanthan S,Ganesan S.Dosimetric characteristics of a MOSFET dosimeter for clinical electron beams. Physica Medica 2009; 25: 1417.

8. Bloemen-Van Gurp EJ,Minken AWH,Mijnheer BJ,Dehing-Oberye Cary JG,Lambin Philips.Clinical implementation of MOSFET dedectors for dosimetry in electron beams. Radiother Oncol 2006;80:288-95. 